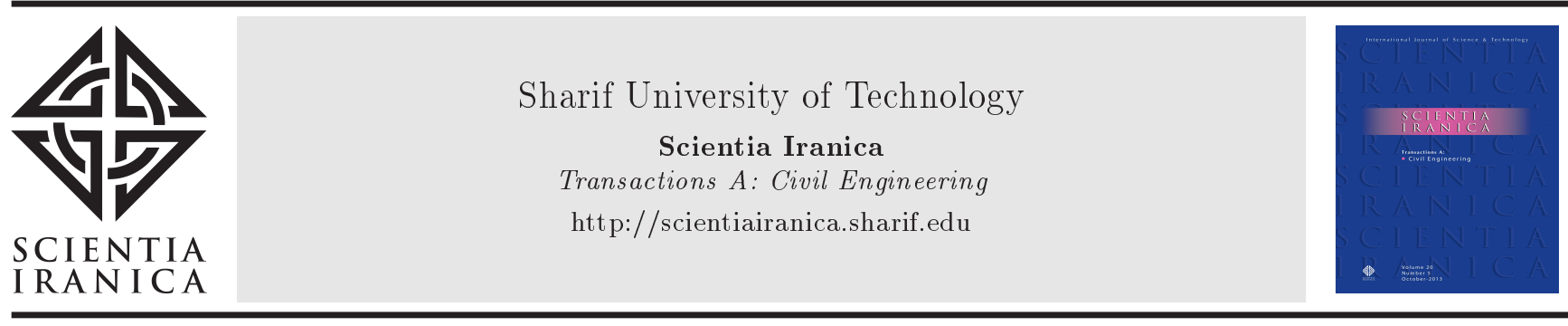

\title{
Government credit risk assessment of non-profit public-private partnership projects in China based on the IVHFSs-IFAHP model
}

\author{
J. Chen and D. Wang* \\ School of Civil Engineering, Nanjing Forestry University, Nanjing 210037, China.
}

Received 5 March 2018; received in revised form 31 August 2018; accepted 3 December 2018

\author{
KEYWORDS \\ Government credit \\ risk assessment; \\ Non-profit PPP \\ projects; \\ WSR methodology; \\ The model of \\ IVHFSs-IFAHP; \\ The private sector.
}

\begin{abstract}
To reduce the financial pressure on local governments and improve operational efficiency, the Chinese government has introduced the Public-Private Partnership (PPP) model for the development of infrastructure. However, the government credit risk generated by PPP projects may damage private and public interests. Therefore, this study evaluated the government credit risks of non-profit PPP projects by using a systematic and rounded model that employed Interval-Valued Hesitant Fuzzy Sets and Intuitionistic Fuzzy Analytic Hierarchical Process (IVHFSs-IFAHP). The perspective of the private sector was employed to establish risk index systems using the dimensions of Wuli-Shili-Renli (WSR) methodology. IFAHP was used to collect expert opinions for the comparison of the importance of the indices and establish an intuitionistic fuzzy judgment matrix in order to calculate the weight of each index. IVHFSs were adopted to obtain the scores of the indices coupled with the results acquired by IFAHP to produce comprehensive scores for them. The feasibility and practicability of the proposed method were empirically verified. The results proved the method to be effective for the private sector to evaluate the government credit risks of non-profit PPP projects, providing a reference for participation in such projects.

(C) 2021 Sharif University of Technology. All rights reserved.
\end{abstract}

\section{Introduction}

In recent years, with the rapid economic development in China, there has been an urge for more and more infrastructure. However, inadequate government funding may limit the development of infrastructure projects. The Public-Private Partnership (PPP) model is an innovative method for delivering such facilities and services to overcome the shortcomings of capital capability, poor management skills, and low levels of technology [1-4]. Accordingly, the method has been widely applied to infrastructure projects in China.

*. Corresponding author. Tel.: +86 13913918561

E-mail address: wjdnjlp@126.com (D. Wang)

doi: $10.24200 /$ sci.2018.50561.1763
However, although it has many advantages, the PPP model faces more complicated risk factors than the traditional delivery model do. Song et al. [5] conducted a multi-case study to identify and analyze factors that would influence early termination in China and revealed that government decision errors and payment defaults were the most common factors. Xu et al. [6] assessed the risk level of a particular critical risk group and the overall risk level associated with PPP projects in China by developing a fuzzy synthetic evaluation model. They showed that government intervention and corruption might be the major hurdles to the success of PPP highway projects in China. Chan et al. [7] used an empirical questionnaire survey and reported that the top three obstacles rated by Beijing respondents were "lengthy delays in negotiations", "lack of experience and appropriate skills," and "lengthy delays due to 
political debates." As can be seen from these studies, the most important risk factors are mostly related to the government. Therefore, it is vital for the private sector to evaluate whether the government has a strong willingness and ability to fulfill its obligations or not. This can be accomplished by assessing its credit risks when the government participates in PPP projects.

A number of studies have been conducted addressing the widespread application of the PPP model to the infrastructure and public services in the world. Zhang et al. [8] found that risk management was the second most popular research topic for PPP projects $(21.7 \%$ and $26.8 \%$ of the total research topics in the Chinese and international journals, respectively). Moreover, Ke et al. [9] showed that the top five frequently cited papers about PPPs focused on risk-related research. They highlighted the importance of risk management research in the field of PPP. Demirag et al. [10] analyzed the risks of PPP projects from the perspective of financiers and stated that it was important for the financiers to work with familiar partners on familiar projects in familiar sectors in order to reduce risks. Moreover, from the perspective of local governments, Shrestha et al. [11] identified the risks, including environmental, competition, and private sector credibility issues, which were unique to the national government. Some scholars have studied the risks of PPP projects in specific fields. Most PPP projects include large green [12], waste-to-energy [13], water [14,15], and freeway PPP projects $[16,17]$. It is evident that the risks associated with PPP projects in different infrastructure sectors vary from sector to sector. While scholars pay particular attention to government-related risks, such as decision-making, corruption, and approval issues, all of these risks are related to the capacity and willingness of a government to fulfill its obligations as well as government credit [18]. Although relevant studies show that the government credit risks of PPP projects are very important, there are only a limited number of articles dealing with this subject.

This paper aims to explore the government credit risk indices of non-profit PPP projects in China by using the Wuli-Shili-Renli (WSR) methodology. Nowadays, most researchers assess the risks of PPP projects by using fuzzy comprehensive evaluation [19], Analytic Hierarchy Process (AHP), Fuzzy Analytic Hierarchy Process (FAHP), Data Envelopment Analysis (DEA) [20], or grey correlation methods. Complexity of objective evaluation, diversity of environments, limitations of human thinking, and different practical experiences of different experts in the government credit risk assessment of non-profit PPP projects make acquiring memberships of the related risk indices, accurately, impossible. Accordingly, the results of studies obtained by the traditional evaluation methods deviate from reality and lack practicality. To better approximate actual results, this paper introduces intuitionistic fuzzy numbers in the assessments [21-23] to represent the memberships of risk factors. In addition, it uses the Intuitionistic Fuzzy Analytic Hierarchy Process (IFAHP) to collect expert opinions on the importance of government credit risk factors in non-profit PPP projects and establishes an intuitionistic fuzzy judgment matrix to calculate the weight of each index. Besides, Interval-Valued Hesitant Fuzzy Sets (IVHFSs) are adopted to obtain the scores of risk factors coupled with the results acquired by IFAHP for achieving comprehensive scores for the factors. Finally, the levels of government credit risks of non-profit PPP projects are obtained. The IVHFSs-IFAHP model developed in this paper can realize the comprehensive evaluation of government credit risks of non-profit PPP projects in China and provide support for the private sector in order to improve its decision-making and management for participation in such projects.

\section{Framework}

The basic process of risk management generally includes risk identification, evaluation, and response. The former two are the most critical steps. Risk identification includes the recognition of the potential causes of risk events in a project and the clarification of the consequences of risk. The main methods of risk identification consist of literature research, case analyses, and expert interviews. Risk evaluation is the process of quantifying the possible degrees of impacts or losses caused by risk events in a project. The most common methods of evaluation are the fuzzy comprehensive evaluation method, AHP, and FAHP. This study is intended to identify government credit risk and evaluate the non-profit PPP projects in China from the perspective of the private sector. The overall research framework of the paper is shown in Figure 1.

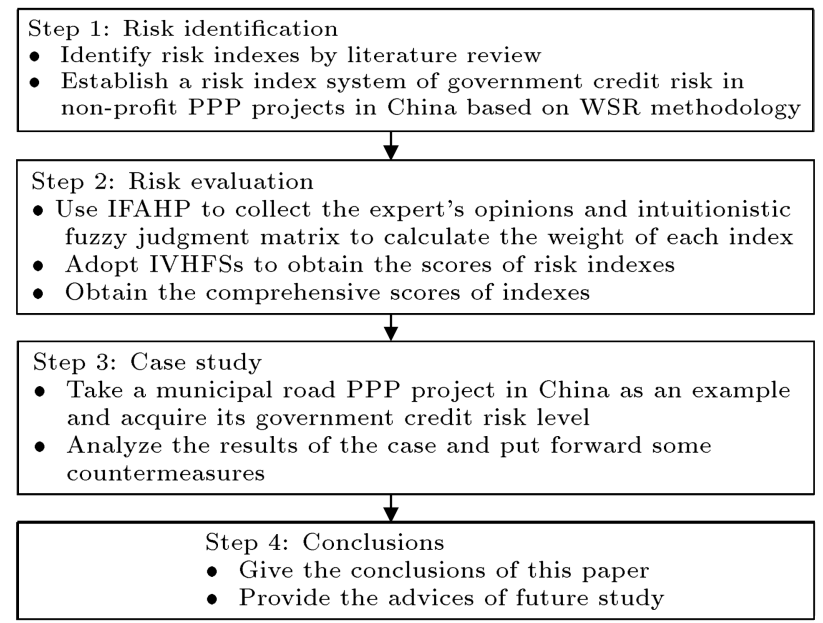

Figure 1. Overall research framework. 


\section{Methodology}

\subsection{Development of the government credit risk index system based on WSR methodology for non-profit PPP projects}

The WSR methodology is a comprehensive integration method for solving complex problems. Its practical guideline is "knowing Wuli, sensing Shili, and caring for Renli" [24-26]. This paper attempts to adopt the WSR theory to establish a risk assessment system for non-profit PPP projects in China from a philosophical perspective.

Based on the characteristics of the research objectives, this study extends the original connotation of the three dimensions in WSR methodology. The "Wuli" dimension represents the objective existence of nature and studies the supporting infrastructure supply and land acquisition that will cause the government credit risk. "Shili" mainly focuses on the laws and regulations, economic contract system, and government management technology of PPP projects. Finally, the "Renli" dimension deals with the impacts of the public sectors on government credit and the mind, purpose, value orientation, and behavior of the public. The WSR model established by this study is shown in Table 1.

\subsection{Development of government credit risk assessment model based on IVHFS -IFAHP}

3.2.1. Definitions of intuitionistic fuzzy sets and IVHSFs

Definition 1: Let $X$ be a non-empty set; then, $A=$ $\left\{<x, u_{A}(x), v_{A}(x)>\mid x \in X\right\}, X=\left\{x_{1}, x_{2}, \cdots, x_{n}\right\}$ is called an intuitive fuzzy set, where $u_{A}(x) \subset[0,1]$, $v_{A}(x) \subset[0,1], 0 \leq u_{A}(x)+v_{A}(x) \leq 1, x \in X$. Moreover, $u_{A}(x)$ and $v_{A}(x)$ represent the degrees of membership and non-membership, respectively, of $x$ in the set $A ; \pi_{A}(x)=1-u_{A}(x)-v_{A}(x)$ represents the hesitancy degree of $x$ in the set $A$; and $0 \leq \pi_{A}(x) \leq 1$, $x \in X$.

Definition 2: Let $X$ be a non-empty set; then:

$$
E=\left\{<x, h_{E}(x)>\mid x \in X\right\}
$$

is called a hesitant fuzzy set, where $h_{E}(x)$ is a collection of the possible membership values $[0,1]$ representing the collection of the memberships of $x$ in the set $E$. $h=h_{E}(x)$ is called a hesitant fuzzy element.

Definition 3: Let $X$ be a non-empty set; then:

$$
\tilde{E}=\left\{<x, \tilde{h}_{\tilde{E}}(x)>\mid x \in X\right\}
$$

is called an IVHFS, where $\tilde{h}_{\tilde{E}}(x)$ is a collection of some sets of interval numbers of $x$ in the set $\tilde{E} . \tilde{h}=\tilde{h}_{\tilde{E}}(x)$ is called an interval-valued hesitant fuzzy element.

\subsubsection{Determining the weights of government credit risk indices}

3.2.2.1. Developing an intuitionistic fuzzy judgment matrix

A group of experts were invited to compare, on the basis of Table 2, any two means of government credit risk indices at the same level to obtain intuitionistic fuzzy judgment matrices. The intuitionistic fuzzy judgment matrix of expert $z(z=1,2, \cdots, k)$ is:

$$
R^{(z)}=\left(r_{i j}^{(z)}\right)_{n \times n}=\left(u_{i j}^{(z)}, v_{i j}^{(z)}\right)_{n \times n},
$$

where $u_{i j}^{(z)}$ represents the importance of the indicators $i$ to $j$ considered by expert $z(z=1,2, \cdots, k)$ and $v_{i j}^{(z)}$ is the importance of the indicators $j$ to $i$. Moreover, $\pi_{i j}^{(z)}=1-u_{i j}^{(z)}-v_{i j}^{(z)}$ represents the hesitancy degree when expert $z(z=1,2, \cdots, k)$ compares the importance of the indicators $i$ and $j$. In this paper, the following considerations are made: $i, j=1,2, \cdots, 7$, $n=7$ in the first-level index system and $i, j=$ $1,2, \cdots, 19, n=19$ in the second-level index system. The number of experts is $k$.

\subsubsection{Consistency check and correction}

The consistency test equation is:

$$
\begin{aligned}
d\left(\bar{R}^{(z)}, R^{(z)}\right) & =\frac{1}{2(n-1)(n-2)} \sum_{i=1}^{n} \sum_{j=1}^{n}\left(\left|\bar{u}_{i j}^{(z)}-u_{i j}^{(z)}\right|\right. \\
& \left.+\left|\bar{v}_{i j}^{(z)}-v_{i j}^{(z)}\right|+\left|\bar{\pi}_{i j}^{(z)}-\pi_{i j}^{(z)}\right|\right)
\end{aligned}
$$

where $R^{(z)}$ represents the intuitionistic fuzzy judgment matrix obtained by comparing any two means of government credit risk indices at the same level by expert $z(z=1,2, \cdots, k)$ and $\bar{R}^{(z)}=\left(\bar{r}_{i j}^{(z)}\right)_{n \times n}$ is the intuitionistic fuzzy judgment consistency matrix calculated by the intuitionistic fuzzy judgment matrix $R^{(z)} \cdot \bar{r}_{i j}^{(z)}$ can be calculated by Algorithm 1 .

\section{Algorithm 1:}

(a) When $j>i+1$, let $\bar{r}_{i j}^{(z)}=\left(\bar{u}_{i j}^{(z)} \bar{v}_{i j}^{(z)}\right) ; \bar{u}_{i j}^{(z)}$ and $\bar{v}_{i j}^{(z)}$ are calculated by Eqs. (2) and (3) as shown in Box I.

(b) When $j=i+1$, let $\bar{r}_{i j}^{(z)}=r_{i j}^{(z)}$;

(c) When $j<i+1$, let $\bar{r}_{i j}^{(z)}=\left(\bar{v}_{i j}^{(z)} \bar{u}_{i j}^{(z)}\right)$.

If $d\left(\bar{R}^{(z)}, R^{(z)}\right)<0.1$, the matrix passes the consistency check; otherwise, $\bar{R}^{(z)}$ should be corrected by Algorithm 2.

Algorithm 2:

Set a parameter $\tau, \tau \in[0,1]$, then: 
Table 1. Government credit risk index system for non-profit Public-Private Partnership (PPP) projects in China based on Wuli-Shili-Renli (WSR) methodology.

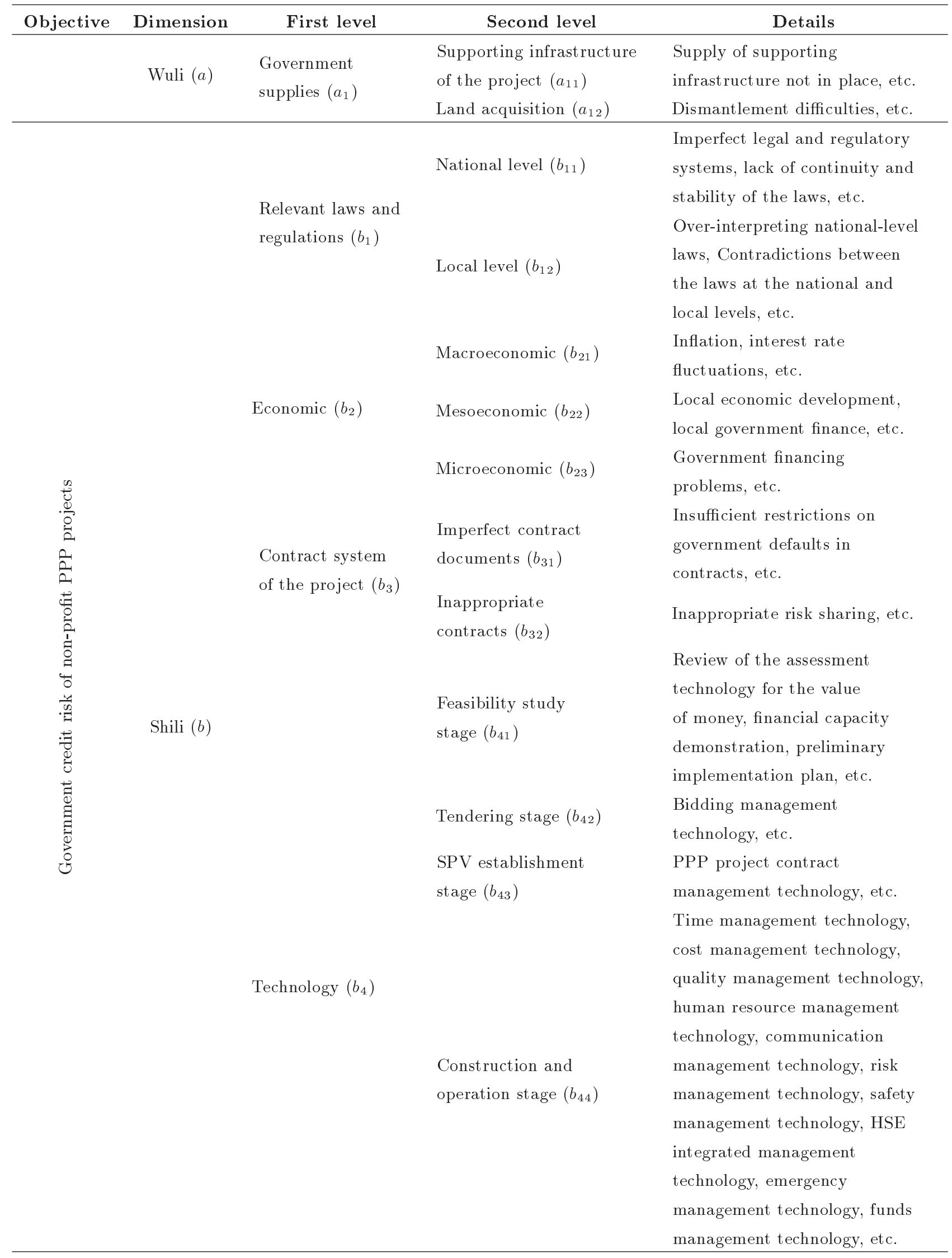


Table 1. Government credit risk index system for non-profit Public-Private Partnership (PPP) projects in China based on Wuli-Shili-Renli (WSR) methodology (continued).

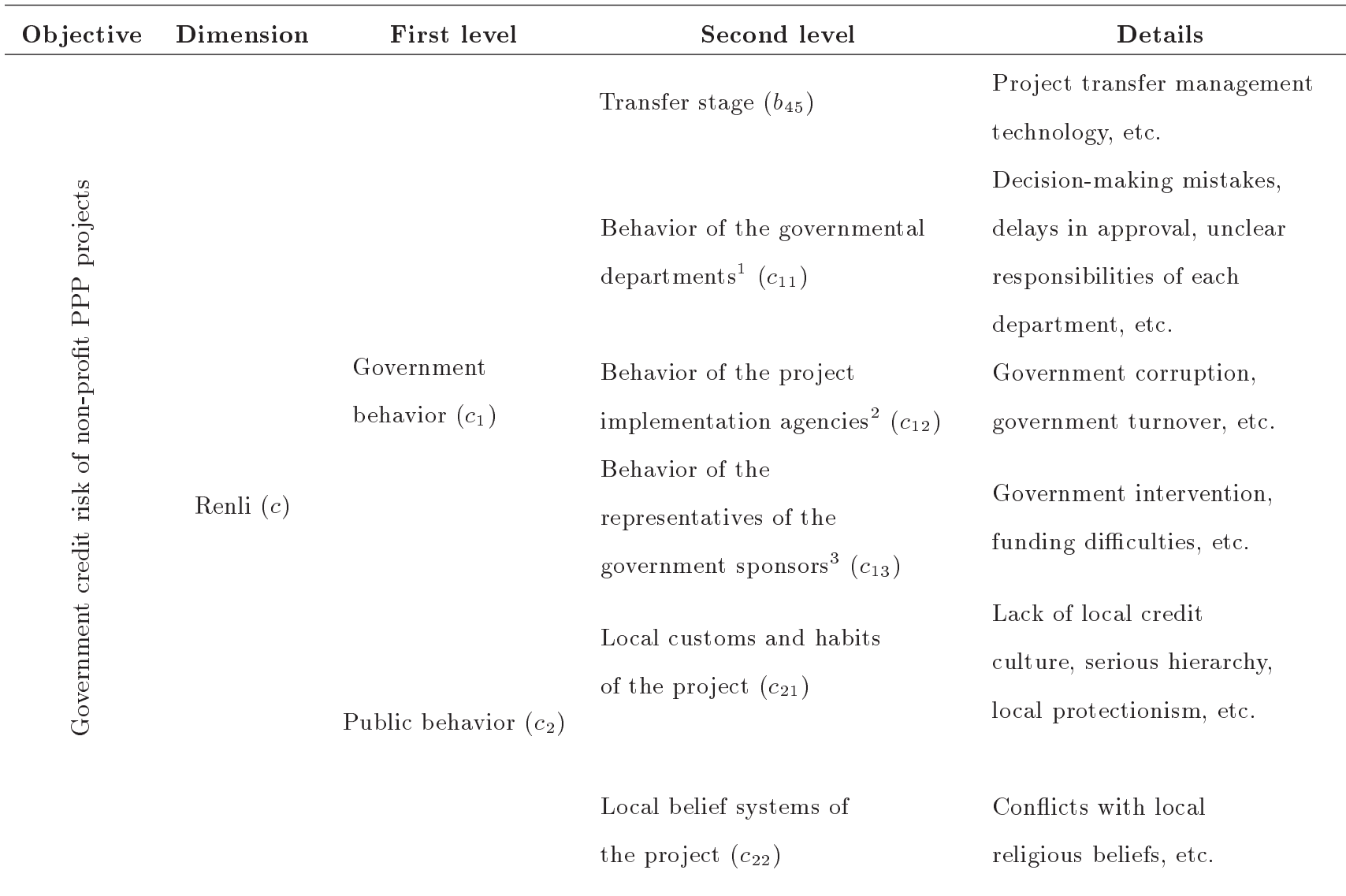

1: The governmental departments in China are responsible for the audit of a PPP project proposal and contract as well as monitoring the costs and performance over the whole life cycle of a project;

2: The project implementation agencies in China are functional departments or government-affiliated institutions designated by the government and they are responsible for the preparation, procurement, supervision, and transfer of specific PPP projects;

3: The government sponsor representatives in China are the main body for fulfilling the obligations of equity investments and sharing the rights of the shareholders on behalf of the government according to the PPP contracts.

$$
\begin{aligned}
& \bar{u}_{i j}^{(z)}=\frac{\sqrt[j-i-1]{\prod_{p=i+1}^{j-1} u_{i p}^{(z)} u_{p j}^{(z)}}}{\sqrt[j-i-1]{\prod_{p=i+1}^{j-1} u_{i p}^{(z)} u_{p j}^{(z)}}+\sqrt[j-i-1]{\prod_{p=i+1}^{j-1}\left(1-u_{i p}^{(z)}\right)\left(1-u_{p j}^{(z)}\right)}} \\
& \bar{v}_{i j}^{(z)}=\frac{\sqrt[j-i-1]{\prod_{p=i+1}^{j-1} v_{i p}^{(z)} v_{p j}^{(z)}}}{\sqrt[i-i-1]{\prod_{p=i+1}^{j-1} v_{i p}^{(z)} v_{p j}^{(z)}}+\sqrt[i-i-1]{\prod_{p=i+1}^{j-1}\left(1-v_{i p}^{(z)}\right)\left(1-v_{p j}^{(z)}\right)}} .
\end{aligned}
$$


Table 2. Complementary judgment matrix.

\begin{tabular}{|c|c|}
\hline Importance comparison & $\begin{array}{l}\text { Importance } \\
\text { assignment }\end{array}$ \\
\hline$i$ is extremely more important than $j$ & $(0.90,0.10,0.00)$ \\
\hline$i$ is powerfully more important than $j$ & $(0.80,0.15,0.05)$ \\
\hline$i$ is significantly more important than $j$ & $(0.70,0.20,0.10)$ \\
\hline$i$ is slightly more important than $j$ & $(0.60,0.25,0.15)$ \\
\hline$i$ is as important as $j$ & $(0.50,0.30,0.20)$ \\
\hline$i$ is slightly less important than $j$ & $(0.40,0.45,0.15)$ \\
\hline$i$ is significantly less important than $j$ & $(0.30,0.60,0.10)$ \\
\hline$i$ is powerfully less important than $j$ & $(0.20,0.75,0.05)$ \\
\hline$i$ is extremely less important than $j$ & $(0.10,0.90,0.00)$ \\
\hline$\tilde{u}_{i j}^{(z)}=\frac{\left(u_{i j}^{(z)}\right)^{1-\tau}\left(u_{i j}^{(z)}\right)}{\left(u_{i j}^{(z)}\right)^{1-\tau}\left(u_{i j}^{(z)}\right)^{\tau}+\left(1-u_{i j}^{(z)}\right)}$ & ${ }^{1-\tau}\left(1-u_{i j}^{(z)}\right)^{\tau}$ \\
\hline$i, j=1,2, \cdots, n$ & $(4)$ \\
\hline$\tilde{v}_{i j}^{(z)}=\frac{\left(v_{i j}^{(z)}\right)^{1-\tau}\left(v_{i j}^{(z)}\right)}{\left(v_{i j}^{(z)}\right)^{1-\tau}\left(v_{i j}^{(z)}\right)^{\tau}+\left(1-v_{i j}^{(z)}\right)^{1}}$ & ${ }^{1-\tau}\left(1-v_{i j}^{(z)}\right)^{\tau}$ \\
\hline
\end{tabular}

The intuition fuzzy consistent judgment matrix $\tilde{R}^{(z)}=$ $\left(\tilde{r}_{i j}^{(z)}\right)_{n \times n}$ adjusted by Algorithm 2 has to undergo another consistency check:

$$
\begin{aligned}
d\left(\tilde{R}^{(z)}, R^{(z)}\right) & =\frac{1}{2(n-1)(n-2)} \sum_{i=1}^{n} \sum_{j=1}^{n}\left(\left|\tilde{u}_{i j}^{(z)}-u_{i j}^{(z)}\right|\right. \\
& \left.+\left|\tilde{v}_{i j}^{(z)}-v_{i j}^{(z)}\right|+\left|\tilde{\pi}_{i j}^{(z)}-\pi_{i j}^{(z)}\right|\right)
\end{aligned}
$$

When the judgment matrix is approved by the consistency check, we can take the next step.

\subsubsection{Determining the weights of the indices at all} levels

(a) Determining the weights of the indices at the first level. After obtaining the intuitionistic fuzzy judgment consistency matrix by the consistency test, the weights of indices at the first level can be calculated by Eq. (7). After that, the arithmetic mean values of the indices at the first level are acquired using Eq. (8). Then, the scoring weights of the indices are calculated by Eq. (9). Finally, they are normalized by Eq. (10).

$$
\begin{gathered}
w_{i}^{(z)}=\frac{\sum_{j=1}^{n} u_{1 j}^{(z)}}{\sum_{i=1}^{n} \sum_{j=1}^{n} u_{i j}^{(z)}}, \frac{\sum_{j=1}^{n} v_{1 j}^{(z)}}{\sum_{i=1}^{n} \sum_{j=1}^{n} v_{i j}^{(z)}}, \\
i=1,2, \cdots, 7 ; \quad z=1,2, \cdots, k, \\
\bar{w}_{i}=\frac{\sum_{z=1}^{5} w_{i}^{(z)}}{5}, \\
H\left(\bar{w}_{i}\right)=\frac{1-\bar{v}_{i}}{1+\bar{\pi}_{i}}, \quad i=1,2, \cdots, 7, \\
\sigma_{i}=\frac{H\left(\bar{w}_{i}\right)}{\sum_{i=1}^{n} H\left(\bar{w}_{i}\right)}, \quad i=1,2, \cdots, 7 .
\end{gathered}
$$

(b) Determining the weights of the indices at the second level. Assuming that the intuitionistic fuzzy judgment matrix of the importance of $\beta$ and $\gamma$ at the second level to $r$ at the first level is called $R_{r}^{(z)}=\left(R_{r \beta \gamma}^{(z)}\right)_{m \times m}, R_{r \beta \gamma}^{(z)}=\left(u_{r \beta \gamma}^{(z)} \cdot v_{r \beta \gamma}^{(z)}\right)$, $\beta, \gamma=1,2, \cdots, 19 ; z=1,2, \cdots, k ; r=1,2, \cdots, 7$, where $u_{r \beta \gamma}^{(z)}$ and $v_{r \beta \gamma}^{(z)}$ represent the comparisons of the importance between $\beta$ and $\gamma$, respectively, at the second level. The consistency test of the intuitionistic fuzzy judgment matrix is carried out by Eqs. (1)-(6). The comprehensive relative weights of the indices at the second level to the indices at the first level $\bar{\sigma}_{\beta \gamma}=\left(\bar{u}_{\beta \gamma}, \bar{v}_{\beta \gamma}\right.$, $\beta, \gamma=1,2, \cdots, 19$ can be calculated by Eqs. (7) and (8). Finally, the comprehensive normalized scoring weights of the indices at the second level are $\left(\sigma^{(2)}\right)^{T}=\left(\sigma_{1}^{(2)}, \sigma_{2}^{(2)}, \cdots, \sigma_{m}^{(2)}\right)$ and can be obtained by Eqs. (9) and (10).

\subsubsection{Determination of index values}

In this study, the aforementioned experts were invited to rate the indices at the second level of the government credit risk in the form of an interval scale. The risk index quantification criteria are shown in Table 3 . The hesitant fuzzy intervals of all the indices were assumed to be between 1 and 9 and the interval length, which is expressed as $h_{i}^{(z)}=\left[h_{i}^{z(-)}, h_{i}^{z(+)}\right]$, was assumed to be less than or equal to 1 . The IVHFSs of index $i$ can be represented as:

$$
\begin{aligned}
h_{i} & =\left\{h_{i}^{(1)}, h_{i}^{(2)}, \cdots, h_{i}^{(k)}\right\} \\
& =\left\{\left[h_{i}^{1(-)}, h_{i}^{1(+)}\right],\left[h_{i}^{2(-)}, h_{i}^{2(+)}\right], \cdots,\left[h_{i}^{k(-)}, h_{i}^{k(+)}\right]\right\} \\
& (i=1,2, \cdots, 19 ; \quad z=1,2, \cdots, k) .
\end{aligned}
$$


Table 3. Risk index quantification criteria.

\begin{tabular}{cl}
\hline Score of the risk index & \multicolumn{1}{c}{ Risk level } \\
\hline$(0,1]$ & Extremely low \\
$(1,2]$ & Very low \\
$(2,3]$ & Low \\
$(3,4]$ & Slightly low \\
$(4,5]$ & Moderate \\
$(5,6]$ & Slightly high \\
$(6,7]$ & High \\
$(7,8]$ & Very high \\
$(8,9]$ & Extremely high \\
\hline
\end{tabular}

The score function for $h_{i}$ is obtained by Eq. (12).

$$
s\left(\tilde{h}_{i}\right)=\sum_{z=1}^{k} \frac{1}{2 k}\left(h_{i}^{k(-)}+h_{i}^{k(+)}\right) .
$$

\subsubsection{Comprehensive score of each risk index}

Assuming that the number of indices at the second level corresponding to the risk index $i$ at the first level is $l$, the comprehensive score of the risk index $i$ can be calculated by Eq. (13):

$$
S_{i}=\sigma_{1}^{(2)} s\left(\tilde{h}_{1}\right)+\sigma_{2}^{(2)} s\left(\tilde{h}_{2}\right)+\cdots+\sigma_{l}^{(2)} s\left(\tilde{h}_{l}\right) .
$$

Afterwards, the score of the government credit risk in the non-profit PPP project is calculated by Eq. (14):

$$
S=\sigma_{1} S_{1}+\sigma_{2} S_{2}+\cdots+\sigma_{7} S_{7} .
$$

Finally, the score acquired by Eqs. (13) and (14) should be compared with the risk level in Table 3 to obtain the comprehensive risk level of the government credit risk.

\section{Case study}

\subsection{Case study process}

The local government in a city in China plans to implement a municipal road project using the PPP model for improving the level of municipal infrastructure management, reducing the pressure of government expenditures, and providing high-quality and efficient services to the public. A private enterprise has the intention to participate in the bidding of the municipal road PPP project, but there are some concerns about whether the government in the project will generate credit risk. Therefore, the company intends to evaluate the government credit risk of the PPP project by the following steps:

Step 1: Establish the government credit risk index system for the municipal road PPP project based on the WSR methodology, as shown in Table 1;

Step 2: Invite five experts to evaluate the risk indices for obtaining the original data and develop the IVHFSs-IFAHP model to process the data. The background information of these experts is shown in Table 4. Taking the indices from $b_{21}$ to $b_{23}$ at the second level as an example, the intuitionistic fuzzy judgment matrix for them acquired by an expert is shown in Table 5.

Eqs. (2) and (3) are used to obtain the intuitionistic fuzzy consistent judgment matrix $\bar{R}$, as shown in Table 6 .

Eq. (1) is used to check the consistency. If the result shows that $d\left(\bar{R}^{(z)}, R^{(z)}\right)=0.1515>0.1$, the test fails. Then, Eqs. (4) and (5) are adopted to modify $\bar{R}$. $\tilde{R}$ at $\tau=0.6$ is shown in Table 7 .

With Eq. $(6), d\left(\tilde{R}^{(z)}, R^{(z)}\right)=0.0896<0.1$ throughout the consistency check. The weights of the indices from $b_{21}$ to $b_{23}$ are computed by Eq. (7) and they can be represented as $(0.3985,0.2862),(0.2758$, $0.3772)$, and $(0.3256,0.3366)$, respectively.

The opinions of the remaining four experts were handled in the same manner using Eqs. (8)-(10) to calculate the comprehensive weights of $b_{21}-b_{23}$, which are shown as $(0.3373,0.3351,0.3276)$. In the same way, the rest of the indices at the first and second levels could be obtained, as shown in Table 8;

\begin{tabular}{|c|c|c|c|c|}
\hline Surname & Title & Work unit & Qualification & Expertise \\
\hline Shen & Professor & Shanghai Jiao Tong University & $\begin{array}{l}\text { Consulting engineer; } \\
\text { Cost engineer }\end{array}$ & Project management \\
\hline Yan & Professor & $\begin{array}{l}\text { Nanjing University of Science and } \\
\text { Technology }\end{array}$ & Consulting engineer & Risk management \\
\hline Huang & Senior engineer & $\begin{array}{l}\text { Huaian Transportation Engineering } \\
\text { Construction Bureau }\end{array}$ & Consulting engineer & Project management \\
\hline $\mathrm{Gu}$ & Senior engineer & $\begin{array}{l}\text { Highway Management Office of } \\
\text { Jiangsu Province }\end{array}$ & Consulting engineer & Contract management \\
\hline Lin & Senior engineer & JSTI Group & Cost engineer & Project financing \\
\hline
\end{tabular}

Step 3: Invite five experts, as mentioned above, to

Table 4. Background information of the experts. 
Table 5. Intuitionistic fuzzy judgment matrix for indices from $b_{21}$ to $b_{23}$ obtained by an expert.

\begin{tabular}{cccc}
\hline & $\boldsymbol{b}_{\mathbf{2 1}}$ & $\boldsymbol{b}_{\mathbf{2 2}}$ & $\boldsymbol{b}_{\mathbf{2 3}}$ \\
\hline $\boldsymbol{b}_{\mathbf{2 1}}$ & $(0.50,0.50)$ & $(0.60,0.30)$ & $(0.45,0.40)$ \\
$\boldsymbol{b}_{\mathbf{2 2}}$ & $(0.30,0.60)$ & $(0.50,0.50)$ & $(0.60,0.25)$ \\
$\boldsymbol{b}_{\mathbf{2 3}}$ & $(0.40,0.45)$ & $(0.25,0.60)$ & $(0.50,0.50)$ \\
\hline
\end{tabular}

Table 6. Intuitionistic fuzzy consistent judgment matrix for indices from $b_{21}$ to $b_{23}$.

\begin{tabular}{llll}
\hline & \multicolumn{1}{c}{$\boldsymbol{b}_{\mathbf{2 1}}$} & \multicolumn{1}{c}{$\boldsymbol{b}_{\mathbf{2 2}}$} & \multicolumn{1}{c}{$\boldsymbol{b}_{\mathbf{2 3}}$} \\
\hline $\boldsymbol{b}_{\mathbf{2 1}}$ & $(0.50,0.50)$ & $(0.60,0.30)$ & $(0.3956,0.5505)$ \\
$\boldsymbol{b}_{\mathbf{2 2}}$ & $(0.30,0.60)$ & $(0.50,0.50)$ & $(0.60,0.25)$ \\
$\boldsymbol{b}_{\mathbf{2 3}}$ & $(0.5505,0.3956)$ & $(0.25,0.60)$ & $(0.50,0.50)$ \\
\hline
\end{tabular}

Table 7. Modified intuitionistic fuzzy consistency matrix.

\begin{tabular}{llll}
\hline & \multicolumn{1}{c}{$\boldsymbol{b}_{\mathbf{2 1}}$} & \multicolumn{1}{c}{$\boldsymbol{b}_{\mathbf{2 2}}$} & \multicolumn{1}{c}{$\boldsymbol{b}_{\mathbf{2 3}}$} \\
\hline $\boldsymbol{b}_{\mathbf{2 1}}$ & $(0.50,0.50)$ & $(0.60,0.30)$ & $(0.4171,0.4896)$ \\
$\boldsymbol{b}_{\mathbf{2 2}}$ & $(0.30,0.60)$ & $(0.50,0.50)$ & $(0.60,0.25)$ \\
$\boldsymbol{b}_{\mathbf{2 3}}$ & $(0.4896,0.4171)$ & $(0.25,0.60)$ & $(0.50,0.50)$ \\
\hline
\end{tabular}

score the degrees of the risk indices at the second level in the form of interval values and calculate the final score of each index by Eqs. (11) and (12). Ultimately, the final score of each index at the first level was obtained by Eq. (13).

Taking the risk index $a_{3}$ as an example, the final score is:

$$
\begin{aligned}
0.3101 & \times 4.65+0.3185 \times 4.70+0.3714 \\
& \times 4.85=4.7402 .
\end{aligned}
$$

The final scores of the remaining indices at the first level are similarly obtained, as shown in Table 8.

Afterwards, the government credit risk score of the municipal road PPP project is calculated using Eq. (13):

$$
\begin{aligned}
0.0881 & \times 3.4822+0.1781 \times 6.9048+0.1326 \\
& \times 4.7402+0.1559 \times 6.7719+0.1336 \\
& \times 5.5394+0.2004 \times 6.9891+0.1113 \\
& \times 3.3292=5.7320
\end{aligned}
$$

\subsection{Analysis of case results}

In this study, the IVHFSs-IFAHP model was employed to evaluate the government credit risk of a municipal road PPP project. The results showed that the government credit risk score was 5.7320 , which was a highlevel risk, meaning that there was a high possibility of generating government credit risk by this project. The score of the governmental behavior risk index on the Renli dimension was 6.9891, which ranked first and was a high-level risk. The risk scores of the relevant laws and regulations and the contract system on the Shili dimension were 6.9048 and 6.7719 , ranking the second and third, respectively, which were slightly high. The scores of the remaining risk indices, including technological, economic, social, and environmental, ranked from fourth to seventh, respectively, and were medium or low.

\subsubsection{Analysis of governmental behavior}

The research shows that any improper actions by the government will lead to a great degree of government credit risk. On the one hand, the project implementation agencies are most likely to cause credit risk, because they will be involved in the whole process of the PPP project and their behavior will have a great impact on it. On the other hand, the private sector is extremely worried that government turnover, the functional adjustment of relevant government agencies, or a change in the responsible person will lead to the government credit risk. Therefore, the government should improve the spirit of the contract while the

\begin{tabular}{|c|c|c|c|c|c|}
\hline No. & $\begin{array}{l}\text { Weights of indices } \\
\text { at the first level }\end{array}$ & $\begin{array}{c}\text { Final scores of indices } \\
\text { at the first level }\end{array}$ & No. & $\begin{array}{l}\text { Weights of indices } \\
\text { at the second level }\end{array}$ & $\begin{array}{c}\text { Final scores of indices } \\
\text { at the second level }\end{array}$ \\
\hline \multirow{2}{*}{$a_{1}$} & \multirow{2}{*}{0.0881} & \multirow{2}{*}{3.4822} & $a_{11}$ & 0.4713 & 3.35 \\
\hline & & & $a_{12}$ & 0.5287 & 3.60 \\
\hline \multirow{2}{*}{$b_{1}$} & \multirow{2}{*}{0.1781} & \multirow{2}{*}{6.9048} & $b_{11}$ & 0.6827 & 7.00 \\
\hline & & & $b_{12}$ & 0.3173 & 6.70 \\
\hline
\end{tabular}
private sector should strengthen communication with the government to solve problems in a timely and effective manner.

Table 8. Weights and final scores of government credit risk indices of the municipal road Public-Private Partnership (PPP) project. 


\subsubsection{Analysis of relevant PPP laws and regulations} The laws and regulations related to the PPP projects are not yet perfect in China and the normative documents issued by the government departments are faulty and vague in some regulations. Furthermore, as a new model, the PPP model does not have enough legal support. Once government credit risk appears, the private sector cannot resort to higher-level laws to safeguard its rights and interests. Hence, China should improve its laws and regulations related to PPP as soon as possible to provide a good legal environment for the operation of PPP projects.

4.2.3. Analysis of contract systems of the PPP project There is not so much practical experience around PPP projects in China, so a unified and agreed-upon model has not yet appeared. The structures of most PPP contracts are relatively complete, but there are some unreasonable designs in the specific terms, which will hinder the success of the projects and increase the probability of government credit risk. Therefore, it is necessary to design the terms of PPP contracts according to local conditions and insert prevention clauses regarding government credit risk.

\subsubsection{Suggestions for private enterprises}

If a private enterprise chooses to participate in a municipal road PPP project in a city, it should improve its communication and coordination levels to request that the government issue the corresponding statements and guarantees when a contract is being negotiated. If the enterprise wins a bid, it should strengthen communications with the government and draft a sound government credit risk prevention and control scheme to protect its own rights and interests.

\section{Conclusions}

As a means of alleviating the financial pressure of local governments, improving the regional environment, creating a good investment and development environment for a city, and providing guarantees for people to live and work in peace and contentment, the Public-Private Partnership (PPP) model has been playing a more and more crucial role in the development of China's infrastructure. However, government credit risk has become a concern for the participation of the private sector in PPP projects.

This paper established a government credit risk index system for non-profit PPP projects in China based on Wuli-Shili-Renli (WSR) methodology and the Interval-Valued Hesitant Fuzzy Sets and Intuitionistic Fuzzy Analytic Hierarchical Process (IVHFSs-IFAHP) model to calculate the comprehensive scores of each risk index and level of government risk. Compared with other evaluation methods, the application of the IVHFSs-IFAHP model could not only reflect the fuzziness of government credit risk index scores of nonprofit PPP projects, but also investigate the degree of hesitation of experts in grading. It could reflect the reliability of government credit risk index scores so as to prevent the loss of information. The research showed that the government risk of non-profit PPP projects in China was at a high level. Therefore, China should speed up the process of PPP legislation, improve the credit system, strengthen the construction of relevant institutions, and improve the contracts of PPP projects to ensure rationality and operability of the terms. Meanwhile, the private sector should carefully evaluate the government credit risks of projects, strive to improve its own abilities, improve the level of coordination and communication, and avoid or correct possible government credit risks. This paper can provide a reference for the private sector to assess government credit risks and make sound decisions when involved in PPP projects. Future research may include:

1. A global study of government credit risks, as there are many differences in government credit risks and indices can be compared. Such a study could provide a reference for the participation of the private sectors in PPP projects around the world;

2. A study on the interval relationships and interaction mechanisms among the government credit risk indices in non-profit PPP projects in order to help the private sector handle government credit risks more effectively.

\section{Acknowledgments}

This work was supported by the Project of Philosophy and Social Science Research in Colleges and Universities in Jiangsu Province (2017SJB0107), and the Excellent Project of Social Science Application Research of Jiangsu Province in 2017-special subject in Finance and Economics Development (17SCQ$10)$.

\section{References}

1. Liu, B., Shen, J.Q., Meng, Z.J., and Sun, F.H. "A survey on the establishment and application of social capital partner selection system for the new profit PPP project", KSCE J. Civ. Eng., 22, pp. 3726-3737 (2018). DOI: $10.1007 / \mathrm{s} 12205-018-0489-5$

2. Xu, Y., Chan, A.P.C., Xia, B., Qian, Q.K., Liu, Y., and Peng, Y. "Critical risk factors affecting the implementation of PPP waste-to-energy projects in china", Applied Energy, 158, pp. 403-411 (2015). DOI: 10.1016/j.apenergy.2015.08.043 
3. Chan, A.P.C., Yeung, J.F.Y., Yu, C.C.P., Wang, S.Q., and Ke, Y.J. "Empirical study of risk assessment and allocation of public-private partnership projects in China", Journal OF Management in Engineering, 27(3), pp. 136-148 (2011). DOI: 10.1061/(ASCE)ME. 1943-5479. 0000049

4. Yuan, J.F., Chan, A.P.C., Xiong, W., Skibniewski, M.J., and Li, Q.M. "Perception of residual value risk in public private partnership projects: critical review", Journal of Management in Engineering, 31(3), p. 04014041 (2013). DOI: 10.1061/(ASCE)ME. 19435479. 0000256

5. Song, J.B., Hu, Y.B., and Feng, Z. "Factors influencing early termination of PPP projects in China", Journal of Management in Engineering, 34(1), p. 05017008 (2018). DOI: 10.1061/(ASCE) ME. 19435479. 0000572

6. Xu, Y.L., Yeung, J.F.Y., Chan, A.P.C., Chan, D.W.M., Wang, S.Q., and Ke, Y.J. "Developing a risk assessment model for PPP projects in chinaa fuzzy synthetic evaluation approach", Automation in Construction, 19(7), pp. 929-943 (2010). DOI: 10.1016/j. autcon. 2010.06. 006

7. Chan, A.P.C., Lam, P.T.I., Chan, D.W.M., Cheung, E., and Ke, Y.J. "Potential obstacles to successful implementation of public-private partnerships in Beijing and the Hong Kong special administrative region", Journal of Management In Engineering, 26(1), pp. 3040 (2010). DOI: 10.1061/ASCE0742-597X201026:130

8. Zhang, S., Chan, A.P.C., Feng, Y.B., Duan, H.X., and Ke, Y.J. "Critical review on PPP Research-A search from the Chinese and international journals", International Journal of Project Management, 34(4), pp. 597-612 (2016). DOI: 10.1016/j. ijproman. 2016. 02. 008

9. Ke, Y.J., Wang, S.Q., Chan, A.P.C., and Cheung, E. "Research trend of public-private partnership in construction journals", Journal of Construction Engineering and Management, 135(10), pp. 1076-1086 (2009). DOI: 10.1061/ASCE0733-93642009135:101076

10. Demirag, I., Khadaroo, I., Stapleton, P., and Stevenson, C. "Risks and the financing of PPP: Perspectives from the financiers", The British Accounting Review, 43(4), pp. 294-310 (2011). DOI: 10.1016/j. bar. 2011. 08. 006

11. Shrestha, A., Chan, T.K., Aibinu, A.A., Chen, C., and Martek, I. "Risks in PPP water projects in China: Perspective of local governments", Journal of Construction Engineering and Management, 143(7), p. 05017006 (2017). DOI: 10.1061/(ASCE)CO. 19437862. 0001313

12. Almarri, K. and Blackwell, P. "Improving risk sharing and investment appraisal for PPP procurement success in large green projects", Procedia - Social and
Behavioral Sciences, 119, pp. 847-856 (2014). DOI: 10.1016/j. sbspro. 2014. 03. 095

13. Song, J.B., Song, D.R., Zhang, X.Q., and Sun, Y. "Risk identification for PPP waste-to-energy incineration projects in China", Energy Policy, 61(9), pp. 953-962 (2013). DOI: 10.1016/j. enpol. 2013. 06. 041

14. Chan, A.P.C., Lam, P.T.I., Wen, Y., Ameyaw, E.E., Wang, S.Q., and Ke, Y.J. "Cross-sectional analysis of critical risk factors for PPP water projects in China", Journal of Infrastructure Systems, 21(1), p. 04014031 (2014). DOI: 10.1061/(ASCE)IS. 1943-555X. 0000214

15. Lee, S. and Choi, J.H. "Wastewater treatment Transfer-Operate-Transfer (TOT) projects in China: The case of hefei wangxiaoying wastewater treatment TOT project", KSCE Journal of Civil Engineering, 19(4), pp. 831-840 (2015). DOI: $10.1007 / \mathrm{s} 12205-013-$ 0095-5

16. Liu, B. and Sun, F.H. "Research on the risk assessment method of PPP project based on the improved matter element model", Sci. Iran., 27(2), pp. 614-624 (2020). DOI: $10.24200 /$ SCI.2018.5295.1187

17. Wu, Y.N., Li, L.W.Y., Xu, R.H., Chen, K.F., Hu, Y., and Lin, X.S. "Risk assessment in straw-based power generation public-private partnership projects in China: A fuzzy synthetic evaluation analysis", $J$. Clean Prod., 161, pp. 977-990 (2017).

18. Zegordi, S.H. and Omid, A. "Efficiency assessment of Iranian handmade carpet company by network DEA", Sci. Iran., 25(1), pp. 483-491 (2018).

19. Valipour, A., Yahaya, N., MD Noor, N., Kildiene, S., Sarvari, H., and Mardani, A. "A fuzzy analytic network process method for risk prioritization in freeway PPP projects: An Iranian case study", Journal of Civil Engineering and Management, 21(7), pp. 933947 (2015). DOI: 10.3846/13923730.2015. 1051104

20. Carbonara, N., Costantino, N., Gunnigan, L., and Pellegtino, R. "Risk management in motorway PPP projects: Empirical-based guidelines", Transport Reviews, 35(2), pp. 162-182 (2015). DOI: 10.1080/ 01441647. 2015. 1012696

21. Aggarwal, S. and Gupta, C. "Sensitivity analysis of intuitionistic fuzzy solid transportation problem", International Journal of Fuzzy Systems, 19(6), pp. 1904-1915 (2017). DOI: 10.1007/s40815-016-0292-8

22. Torra, V. "Hesitant fuzzy sets", International Journal of Intelligent Systems, 25(6), pp. 529-539 (2010). DOI: 10.1002/int. 20418

23. Chen, S.W. and Cai, L.N. "Interval-valued hesitant fuzzy sets", Fuzzy Systems and Mathematics, 27(6), pp. 38-44 (2013).

24. Gu, J.F. and Tang, X.J. "From ancient system thoughts to modern oriental systems methodology", Systems Engineering-Theory \& Practice, 20(1), pp. 89-92 (2000). 
25. Gu, J.F. and Zhu, Z.C. "Knowing wuli, sensing shili, caring for renli: methodology of the WSR approach", Systemic Practice \& Action Research, 13(1), pp. 11-20 (2000).

26. Zhu, Z.C. "Dealing with a differentiated whole: the philosophy of the WSR approach", Systemic Practice \& Action Research, 13(1), pp. 21-57 (2000).

\section{Biographies}

Jia Chen is an MSc student in the School of Civil Engineering at Nanjing Forestry University. She received her BSc degree from the School of Civil Engineering, Nanjing Forestry University, in 2015. Her research interests include engineering management as well as PPP model and its application to infrastructure projects.

Daming Wang is an Associate Professor in the School of Civil Engineering at Nanjing Forestry University. His research interests include project management as well as pavement structure and material. He has published many papers in reputable journals and international conference proceedings and a number of book chapters. 